\title{
The Role of p53 Gene Family in Reproduction
}

\author{
Wenwei Hu \\ Cancer Institute of New Jersey, University of Medicine and Dentistry of New Jersey, New Brunswick, \\ New Jersey 08903 \\ Correspondence: huw1@umdnj.edu
}

The p53 family of genes ( $p 53$, p63, and p73) is conserved over evolutionary time scales. Although the functions of p53 gene and its protein as a tumor suppressor have been firmly established, the earliest functions for the p53 ancestral genes in worms and flies are to ensure germ-line genomic integrity and the fidelity of the developmental process. In vertebrates, the p53 family of genes retains those functions in germ-line genomic integrity but have added important functions in regulation of reproduction. Loss of the p53, p63, or p73 genes in female mice leads to a significant decrease of fertility. The p53 gene product regulates maternal reproduction at the implantation stage of the embryo. p63 and p73 play important roles in monitoring the genomic quality of oocytes. The p53 pathway appears to play a similar role in human fertility. In humans, certain alleles containing a functional single-nucleotide polymorphism (SNP) in the p53 pathway are under positive evolutionary selection. Selected alleles of these SNPs in the p53 pathway are associated with decreased fertility. This important function of the p53 pathway in reproduction provides a plausible explanation for the evolution of p53 as a tumor suppressor gene and the positive selection of some alleles in the p53 gene and its pathway. These observations provide a good possible example of antagonistic pleiotrophy for fertility, tumor suppression, and longevity.

$T^{1}$ he tumor suppressor protein p53 plays a crucial role in maintaining genomic stability in somatic cells and preventing tumor formation (Levine et al. 2006). The $\mathrm{p} 53$ protein acts as a DNA sequence-specific transcription factor and regulates an appropriate cellular response to various stress signals. In response to stress, activated p53 selectively transcribes a set of target genes that initiate various cellular responses including cell cycle arrest, DNA repair, apoptosis, or senescence. These programs eliminate cells with damaged and mutated genomes before they become nascent tumor cells. As the "guardian of the genome," disruption of normal p53 function is in some circumstances a prerequisite for the development or progression of tumors (Vogelstein et al. 2000; Harris and Levine 2005; Levine et al. 2006). p53 is the most frequently mutated gene in human tumors. Over $50 \%$ of tumors harbor mutations in the p53 gene, and over $80 \%$ of tumors have dysfunctional p53 signaling (Bennett et al. 1999).

Editors: Arnold J. Levine and David Lane

Additional Perspectives on The p53 Family available at www.cshperspectives.org

Copyright (C) 2009 Cold Spring Harbor Laboratory Press; all rights reserved; doi: 10.1101/cshperspect.a001073

Cite this article as Cold Spring Harb Perspect Biol 2009;00:a001073 
W. Hu

\section{THE PRIMORDIAL FUNCTIONS OF THE p53 FAMILY GENES IN INVERTEBRATES}

The $\mathrm{p} 53$ family genes are conserved from invertebrates to mammals (Belyi et al. 2010). The homologs of the p53 family gene members have been described in many different organisms, including sea anemone, clams, Caenorhabditis elegans, Drosophila, frogs, and zebra fish, etc. (Soussi et al. 1987; Cheng et al. 1997; Jin et al. 2000; Derry et al. 2001; Kelley et al. 2001; Nedelcu and Tan 2007; Pankow and Bamberger 2007; Fernandes and Atchley 2008). The existence of homologs of the p53 family of genes in lower organisms, which have short life spans and do not acquire cancer as adults, such as flies and worms, suggests that tumor suppression may not be the original function for the p53 family of genes. Rather, the evidence shows that the p53 family genes function in development and fecundity. In the sea anemone (Nematostella vectensis), the p53-like protein nvp63 is highly expressed in germ-cell compartments of adult polyps and mediates UV irradiation-induced apoptosis of gametes (Pankow and Bamberger 2007). Here, the p53-like protein plays a critical role in maintaining the integrity of the genome transmitted to the next generation to avoid deleterious mutations, which would increase the cost of reproduction of the species if not selected against before fertilization. Similarly, in Drosophila and C. elegans, a p53-like protein is most commonly expressed in germ cells. C. elegans contains a single p53 family member, CEP-1 (C. elegansp53-like-1). CEP-1 functions in the surveillance of damaged DNA in germ cells to eliminate defective offspring from the population by inducing germline apoptosis on DNA damage induced by $\gamma$-irradiation (Ollmann et al. 2000; Derry et al. 2001). In Drosophila, Drosophila p53 (Dmp53) plays an important role in regulating germ-cell development and maintaining the integrity of the germ line. Dmp53 is required for DNA damageinduced apoptosis of primordial germ cells through transcriptional activation of two tightly linked cell-death activators, reaper and sickle (Brodsky et al. 2000a; Sogame et al. 2003). Dmp53 null mutants show genomic instability, especially in response to $\gamma$-irradiation, which further shows a critical role of Dmp53 in maintaining the genomic integrity of germ cells (Sogame et al. 2003). Furthermore, Dmp53 is also involved in the developmental processes of the ovary. Dmp53 null mutants have degenerative ovarioles and decreased fertility compared with their parental strain (Lee et al. 2003). Interestingly, decreased fertility is also observed in mei-41 and Dmchk2 null Drosophila (Mason et al. 1981; Banga et al. 1995; Brodsky et al. 2000b; Xu et al. 2001). The products of these genes are homologous to mammalian DNA damage-induced kinases, ATM and Chk2, respectively, which activate $\mathrm{p} 53$ protein on DNA damage (Canman et al. 1998; Hirao et al. 2000; Shieh et al. 2000). These observations, taken together, show the critical role of the ancestral p53 pathway of genes in protecting female germ cells and fertility.

\section{THE ROLE OF THE p53 FAMILY GENES IN REPRODUCTION IN VERTEBRATES}

In vertebrates, p53 family of genes includes three genes for the $\mathrm{p} 53$, p63, and $\mathrm{p} 73$ proteins. These three members of the p53 family share a very high homology, with p63 and p73 being more closely related to each other than to p53 (Yang et al. 1998; Melino et al. 2003; Moll and Slade 2004; Bourdon et al. 2005). They all contain several conserved protein domains: An amino-terminal transactivation (TA) domain, a DNA binding domain (DBD), and an oligomerization domain (OD). In addition to these three domains, p63 and p73 contain in their carboxyl terminus a protein-protein interaction domain known as the "sterile alpha motive" (SAM) and a transcription inhibition domain (TID). These three members of the p53 gene family give rise to multiple protein products resulting from both alternative promoter usage and alternative mRNA splicing (Yang et al. 1998; Moll and Slade 2004; Bourdon et al. 2005). p53 family genes all have two promoters: one upstream from exon one that generates isoforms containing TA domain, and one intronic that generates 
amino-terminal truncated isoforms that function as dominant-negative inhibitors of the p53 family. Furthermore, carboxy-terminal splicing generates a variety of TA and $\Delta \mathrm{N}$ isoforms that give rise to additional structural and functional diversity. Although p63 and p73 are the more recently identified p53 family members, it appears that p63 and p73 genes are ancestral to p53 and possibly evolved from a p63/ p73-like gene (Nedelcu and Tan 2007).

The p53 family genes in vertebrates appear to retain their primordial functions in germline surveillance and reproduction. In Xenopus laevis, p53-dependent transcription is activated during early oogenesis and the p53 levels remain relatively high during development. Inactivation of the $\mathrm{p} 53$ function prevents normal development of the Xenopus embryo (Hoever et al. 1994). In mice and rats, the p53 levels are very high during spermatogenesis. p53 null mice or mice with reduced levels of p53 show some germ-cell degeneration during the meiotic prophase, with a high frequency of multinucleated giant cells within the testicular seminiferous tubules (Rotter et al. 1993). p53 also mediates stress-induced spermatogonial apoptosis after DNA damage (Hasegawa et al. 1998). In mouse embryos, p53 is expressed at high levels until the mid-gestation stage (Schmid et al. 1991). Furthermore, the p53dependent DNA damage responses (transcriptional activation and apoptotic response) are highly active throughout this period of development (Nicol et al. 1995; Norimura et al. 1996). In response to IR, wild-type embryos show a p53 dependent apoptosis, which results in a high percentage of death to efficiently eliminate the damaged offspring, whereas p53-/embryos show a very small percentage of death and a correspondingly high percentage of developmental abnormalities.

p53 also regulates reproduction in mice. Loss of p53 in mice causes a significant decrease in fertility in a gender-specific manner. p53 null female mice, but not p53 null male mice, have significantly decreased fertility ( $\mathrm{Hu}$ et al. 2007b). In C57BL/6J mice, the pregnancy rate and the litter size for $\mathrm{p} 53-/-$ female mice mated with $\mathrm{p} 53+/+$, p $53+/-$, or p $53-/-$ males decrease dramatically and the decrease appears to be most severe when p53-/females are mated with p53-/- males with the genotype of their embryos being p53-/A similar observation was made with the $129 \mathrm{SV}^{\mathrm{sl}}$ strain of mice, although the phenotype is less severe, suggesting that there are strainspecific modifier genes that influence this function of the p53 protein. p53 regulates maternal reproduction at implantation stage through its target gene, leukemia inhibitory factor (LIF), a multifunctional cytokine ( $\mathrm{Hu}$ et al. 2007b; Hu et al. 2008). LIF plays a crucial role in blastocyst implantation (Stewart et al. 1992; Vogiagis and Salamonsen 1999; Chen et al. 2000). Implantation is a critical stage in mammalian embryonic development during which the blastocyst establishes a close interaction with the uterine tissues, which leads to the formation of the placenta to support the growth and development of the fetus. In many mammalian species, including mouse and human, transiently increased expression of LIF in uterus, which is regulated by estrogen and p53, is coincident with the onset of implantation. Highly expressed in the endometrial glands, LIF protein is secreted into the uterine lumen and binds to its receptors on the surface of epithelial cells, preparing the uterus to be receptive to the implantation of the blastocyst, a procedure called decidualization. LIF null mice have a defect in maternal reproduction caused by the complete lack of uterine decidualization at the implantation stage and the failure of blastocyst implantation, which can be rescued by LIF injection at the implantation stage (the 4th day of pregnancy in mice) (Chen et al. 2000). Similarly, p53 null mice have an impaired implantation function because of the significantly decreased uterine LIF levels, especially at the onset of implantation, when the sufficient LIF levels are crucial for blastocyst implantation. Administering LIF to p53 null female mice at day 4 of pregnancy significantly increases their fertility with improved blastocyst implantation (Fig. 1) (Hu et al. 2007b).

p63 and p73 also play important and unique roles in development and reproduction. p63 is expressed in a highly restricted pattern during 
W. Hu

A

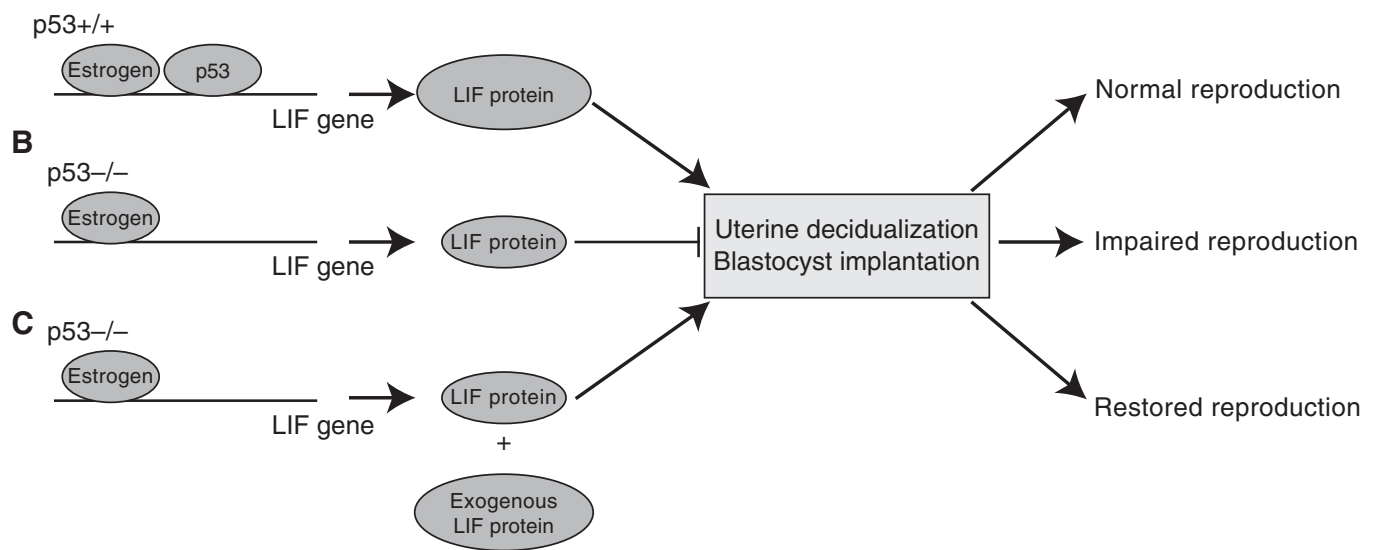

Figure 1. p53 regulates maternal reproduction through LIF in mice. At the implantation stage in mice (day 4 of pregnancy), estrogen (E2) and p53 induce uterine LIF expression at sufficient levels, which is crucial for uterine decidualization and implantation of blastocysts $(A)$. p53 loss decreases uterine LIF levels at the implantation stage, which leads to impaired function in uterine decidualization and implantation $(B)$. Administration of exogenous LIF to p53-/- mice at day 4 of pregnancy could restore reproduction by improving implantation $(C)$.

embryonic development and its expression is absolutely essential for limb formation and epidermal morphogenesis (Mills et al. 1999; Yang et al. 1999). p63 is expressed within the primitive ectoderm, which gives rise to the epidermis as well as epithelial appendages, and in the apical ectodermal ridge, a specialized cluster of ectodermal cells required for inductive events during limb formation. p63-null mice show profound developmental abnormalities of the skin, limbs, mammary, prostate, and other epithelial tissues. Although the predominant isoforms expressed during development are amino-terminally truncated $\Delta \mathrm{N}$ form, strong expression of $\Delta \mathrm{Np} 63$ and TAp63 is observed in mouse reproductive organs (Kurita et al. 2005) and primordial germ cells (Nakamuta and Kobayashi 2004b). Expression of p63 is detected in the mouse testis (Nakamuta and Kobayashi 2003; Nakamuta and Kobayashi 2004a). Both $\Delta \mathrm{Np} 63$ and TAp63 are found in nucleus of germ cells in mouse testis from E13.5 to E18.5. $\Delta \mathrm{Np} 63$ is expressed at several specific stages of testicular development, from day 1 to day 7 and from 3 weeks to 4 weeks after birth. In female mouse reproductive organs, $\Delta \mathrm{Np} 63$ is expressed in epithelium in the cloaca and urogenital sinus at E12, and in Mullerian duct epithelial cells at E18. The expression of p63 in the genital tract plays an important role in its development and is an identity switch for Mullerian duct epithelium to become cervicovaginal versus uterine tissue (Kurita et al. 2004). p63-null mice show abnormal genital morphogenesis with hypoplastic genitalia, a single cloacal opening, and persistence of columnar epithelium at lower genital tract sites that normally undergo squamous and urothelial differentiation. High TAp63 expression is detected in ovary and its expression in ovaries progressively increases when developing oocytes go through nonreductive DNA replication and homologous chromosome recombination between E13 and E18.5 and then arrest in prophase of meiosis (Kurita et al. 2005; Suh et al. 2006). TAp63 is not essential for development of oocytes, ovaries, or follicles, as ovaries from p63 null mice are histologically normal. The important role of TAp63 is to protect female germ-line fidelity during meiotic arrest, a prolonged arrest in prophase of meiosis I between homologous chromosome recombination and ovulation. TAp63, in particular TAp63 $\alpha$, is phosphorylated on DNA 
damage. It monitors the repair of DNA damage and induces p53-independent apoptosis of oocytes in response to DNA damage to control female germ-line integrity. Oocytes from TAp63 null mice or p63 null mice are completely resistant to DNA damage induced by $\gamma$ irradiation (Suh et al. 2006; Livera et al. 2008). As the pool of primordial follicles determines female fertility in mammals and low doses of irradiation induce loss of primordial follicles in the ovary, p63 may likely regulate the female fertility by protecting the fidelity of the female germ line. This is an example that the p53 family functions in maintaining germ-cell fidelity in a gender-specific manner. Radiosensitivity of male germ cells and DNA damageinduced male germ-cell death are p53 dependent, whereas irradiation-induced female germ-cell death is p63 dependent.

p73 also has distinct roles in development and reproduction. The major p73 isoforms expressed during mouse embryonic development are $\Delta \mathrm{Np} 73$. Strong $\Delta \mathrm{Np} 73$ expression is observed in E12.5 fetal mouse brain in the preplate layer, bed nucleus of stria terminalis, choroids plexus, vomeronasal area, and preoptic area. Mice deficient for all p73 isoforms are viable, but are runted and have high rates of mortality. These mice show profound developmental defects, including hippocampal dysgenesis, hydrocephalus, chronic infections, and inflammation (Yang et al. 2000). Moreover, p73 null male mice are not interested in mating with sexually matured females and are infertile. This is because of a dysfunction of the vomeronasal organ, an accessory olfactory structure involved in pheromone detection, which normally expresses high levels of p73 (Yang et al. 2000). TAp73 has an important function in regulation of spindle assembly checkpoint (SAC) functions during meiosis and mitosis (Tomasini et al. 2008). SAC complex contains more than 20 proteins, including MAD2, BUB1, BUB3, BUBR1, and cyclin B1. SAC prevents aneuploidy through sensing the improper attachment of sister chromatids to the mitotic or meiotic spindle and delays anaphase until all chromosomes are correctly oriented for segregation (Gardner and Burke 2000; Taylor et al.
2004). In mice, a deficiency of BUBR1 promotes infertility and premature aging (Baker et al. 2004). TAp73 interacts directly with several components of the SAC (BUB1 and BUBR1) and regulates their activity. In this way, the loss of TAp73 can lead to increased genomic instability and aneuploidy in the germ cells (Tomasini et al. 2009). Indeed, TA73 knockout mice are infertile. Oocytes from TAp73 knockout mice show a striking increase in aneuploidy and spindle abnormalities. Oocytes from TAp73 knockout mice have poor developmental competence and often have a failure in preimplantation development. The majority of embryos obtained from TAp73 knockout oocytes arrest during early cleavage, resulting in embryos with multinucleated blastomeres, and blastocysts of poor quality. TAp73 knockout female mice also have less oocytes ovulated and a greater number of oocytes remain trapped within the luteinizing granulose cells of ovaries (Tomasini et al. 2008). Decreased fecundity occurs with increasing maternal age, and poor quality of female germ cells, which will result in abnormal embryonic development, is thought to be the major underlying cause (Spandorfer et al. 2004). Interestingly, TAp73 expression in oocytes declines with natural aging, and oocytes from young TAp73 knockout mice and aged wild-type mice have a similar spectrum of spindle abnormalities (Tomasini et al. 2008), suggesting that TAp73 is involved in maintaining genomic stability in female germ-line cells and the loss of TAp73 may contribute to the increased aneuploidy produced by aged normal oocytes.

\section{THE ROLE OF THE p53 PATHWAY IN REPRODUCTION IN HUMANS}

Given the evolutionarily conserved functions of the p53 family in fertility through maintaining germ-cell integrity and various steps in reproduction, one would expect that this family plays a similar role in both mice and humans. In humans, SNPs have been identified in genes at critical nodes in the p53 pathway, including p53, Mdm2, Mdm4, and Hausp (Bond et al. 2004; Murphy 2006; Atwal et al. 2009; Kang 
W. Hu

et al. 2009). Some of these SNPs have known functional variations that can modify the levels or activity of the p53 protein and the Mdm2 protein. Thus, some individuals will have higher p53 activities (the p53 codon 72 arginine allele) and others will have higher Mdm2 levels (the Mdm2 SNP309 G-residue) and less p53 protein and activity. Interestingly, recent studies of the haplotype structures of these SNPs in the p53, Mdm2, Mdm4, and HAUSP genes in populations with different ethnic backgrounds show that certain alleles in the p53 gene and the gene products that regulate the p53 protein are under evolutionary selection pressures in Caucasian populations (Atwal et al. 2007; Atwal et al. 2009; Kang et al. 2009). Reproduction is much more likely to be the nature of the observed evolutionary selection pressure, because the impact of the p53 protein in cancer prevention or longevity occurs mainly in postreproductive years. This suggests that p53 may regulate human reproduction. In the human p53 gene, a common coding SNP at codon 72 results in either an arginine (Arg) or a proline (Pro) residue in the protein at codon 72 . The p53 Pro allele is weaker than the p53 Arg allele in inducing apoptosis and suppressing cellular transformation, and is associated in some tumors with an earlier onset of tumor formation (Dumont et al. 2003; Sullivan et al. 2004); but, the p53 Pro allele appears to be better at initiating senescence and cell cycle arrest (Pim and Banks 2004; Salvioli et al. 2005). The allele frequencies of p53 codon 72 are significantly different in populations with different ethnic background. The Pro allele appears to be the ancestral allele by comparison with chimpanzee DNA, and has approximately $60 \%$ frequency in diverse African populations but becomes the minor allele $(25 \%-35 \%)$ in Caucasian populations. $\mathrm{Mdm} 2$ is a crucial negative regulator of $\mathrm{p} 53$, which forms a central node within the p53 pathway. Mdm2 SNP309 contains a T to G change in the intronic promoter region. The SNP309 G allele increases the DNA binding affinity of the transcriptional activator Sp1, which results in higher transcription levels of $\mathrm{Mdm} 2$ and the attenuation of the p53 pathway
(Bond et al. 2004). Furthermore, SNP309 is in a region that is directly regulated by estrogen signaling. Estrogen preferentially stimulates the transcription of Mdm2 with the SNP309 $\mathrm{G}$ allele ( $\mathrm{Hu}$ et al. 2007a). In humans, the SNP309 G allele is associated with accelerated tumor onset and increased risk for cancers, especially for women before menopause. The frequencies of Mdm2 SNP309 also differ greatly among different ethnic backgrounds. The $\mathrm{T}$ allele is the ancestral allele and the $\mathrm{G}$ allele arose more recently. The $\mathrm{G}$ allele frequency is only 10\% in African Americans and this 10\% in African Americans appears to be contributed by an admixture with Caucasians, but its frequency is approximately $43 \%$ in Caucasian Americans. The study on the haplotype structures of the Mdm2 gene shows that there are many different haplotypes for the T allele, whereas there is only one G-allele haplotype found in Asian and Caucasian populations. Similarly, the Mdm4 gene and the Hausp (Herpes virus-associated ubiquitin-specific protease) gene appear to have haplotypes in Caucasians under positive selection. Both Mdm4 and Hausp are critical regulators of the p53 protein. Mdm4, a structural homolog of Mdm2, binds to the amino terminus of p53 and is a key inhibitor of this protein. HAUSP can stabilize Mdm2, Mdm4, and p53 as a specific deubiquitinase and is an important regulator of the p53 pathway (Brooks et al. 2007). For the Mdm4 gene, the allele containing an SNP (a T to C change) (rs2279744) appears to be under evolutionary selection pressures. The $\mathrm{T}$ allele is the ancestral allele and the $\mathrm{C}$ allele arose more recently. The $\mathrm{C}$ allele frequency is only 30\% in African Americans and up to $67 \%$ in Caucasians (a very rapid switch over the past 30,000 years). Furthermore, there is a single dominant $\mathrm{C}$-allele haplotype and many different haplotypes for the ancestral Tallele in Caucasians. In the Hausp gene, the allele containing an SNP (a G to A change) (rs1529916) appears to be under evolutionary selection pressure as well. The $\mathrm{G}$ allele is the ancestral allele and the $\mathrm{A}$ allele arose more recently. The A allele frequency is only $16 \%$ in African Americans and up to $33 \%$ in Caucasians. 
There are many different haplotypes for the $\mathrm{G}$ allele (the ancestral allele), whereas there is only one A-allele haplotype found in Caucasians (arose more recently). Considering the recent establishment of the Arg allele of p53, the $\mathrm{G}$ allele haplotype of $\mathrm{Mdm} 2$, the A allele haplotype of Hausp, and the $\mathrm{C}$ allele haplotype of Mdm4 in the Caucasian populations, along with their relatively high frequency in Caucasian and Asian populations, these observations suggest that these haplotypes are under positive selection in these racial groups, and indicate the presence of candidate functional SNPs in these haplotypes that influence p53 function in reproduction.

Indeed, selected alleles of SNPs of p53, Mdm2, Mdm4, and Hausp are associated with decreased fertility in humans (Fig. 2). The enrichment of the p53 Pro allele is observed in in vitro fertilization (IVF) patients with unexplained infertility (Table 1) (Kang et al. 2009) but particularly in patients with recurrent implantation failure (Kay et al. 2006). Furthermore, the p53 Pro allele serves as a risk factor for implantation failure and decreased pregnancy rate after an IVF procedure (Kang et al. 2009). Although the women homozygous for the p53 Pro allele have normal ovary function, and embryos obtained from oocytes of these patients have a normal developmental

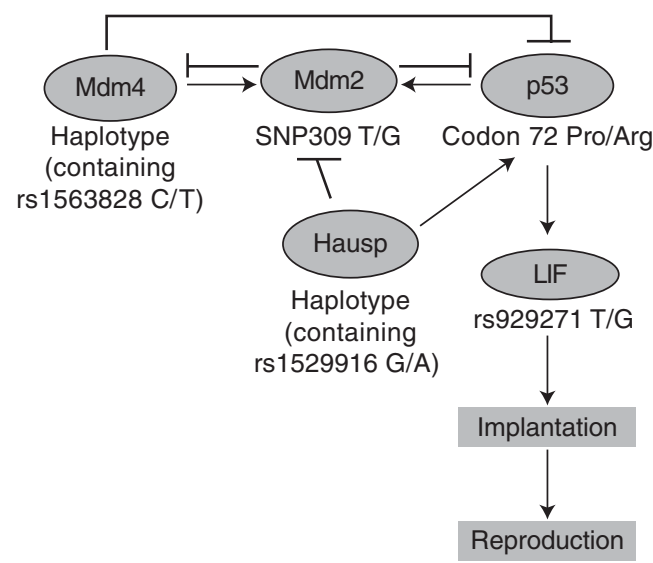

Figure 2. SNPs in the p53 pathway associated with human fertility. Naturally occurring polymorphisms in the p53 pathway listed in the diagram, which modify the function of the $\mathrm{p} 53$ pathway, could have an impact on human fertility. competence. These patients have a significantly lower implantation rate after an IVF procedure compared with patients carrying at least one Arg allele. This would be caused by the decreased LIF expression levels associated with the p53 Pro allele. In humans, LIF is highly expressed in the uterine endometrium at the time of implantation and plays an important role in the initial attachment of the blastocyst to the endometrium for a successful implantation. Implantation is relatively inefficient in humans and often is the major cause for the pregnancy failure after an IVF procedure. Deceased uterine LIF levels are often associated with decreased fertility in humans. Immunoreactive LIF is reduced in endometrial biopsies from infertile women and LIF is also reduced in uterine flushings from women with primary infertility compared with fertile controls (Tsai et al. 2000; Mikolajczyk et al. 2007). The p53 Pro allele is weaker in transcriptional activation toward a subset of p53 target genes, including LIF, than the p53 Arg allele. LIF expression levels are about twofold lower in cells with the p53 Pro allele compared with the p53 Arg allele, which may lead to the decreased implantation rate and fertility. A genetic association is also observed between an SNP (a T to G change) at $3^{\prime}$ UTR of human LIF gene and human fertility (Table 1 , Fig. 2). The enrichment of the $G$ allele (the minor allele) is observed in the IVF patients, and the same G allele is also associated with a history of fertility medication used in normal or control population of women (Kang et al. 2009). Furthermore, selected alleles of SNPs in Mdm2, Mdm4, and Hausp genes are all enriched in IVF patients (Table 1) (Kang et al. 2009), suggesting that these SNPs have an impact on human fertility through attenuation of the p53 pathway, which might result in a low LIF expression level at the implantation stage. Therefore, it would be expected that for these patients undergoing an IVF procedure, providing LIF to them at the implantation stage might enhance their chance for pregnancy. This has not been tested in the clinic yet. These results clearly show the association of SNPs in the p53 pathway with human fertility and 
W. Hu

Table 1. Selected alleles of genes in the p53 pathway are associated with decreased fertility in humans

\begin{tabular}{|c|c|c|c|c|c|c|}
\hline \multirow[b]{3}{*}{ Gene } & \multirow{3}{*}{$\begin{array}{c}\text { Genotype } \\
\text { of SNP }\end{array}$} & \multirow[b]{3}{*}{ Control $n(\%)$} & \multicolumn{4}{|c|}{ IVF patients } \\
\hline & & & \multicolumn{2}{|c|}{$<35$ years } & \multicolumn{2}{|c|}{$\geq 35$ years } \\
\hline & & & $n(\%)$ & $p^{a}$ & $\mathrm{~N}(\%)$ & $\mathrm{p}^{\mathrm{a}}$ \\
\hline \multirow[t]{6}{*}{ p53 (rs 1042522) } & GG & $710(60.6)$ & $68(41.0)$ & $2.8 \mathrm{E}-05^{\mathrm{b}}$ & $53(50.0)$ & 0.13 \\
\hline & GC & $392(33.4)$ & $79(47.6)$ & & $43(40.6)$ & \\
\hline & $\mathrm{CC}$ & $70(6.0)$ & $19(11.4)$ & & $10(9.4)$ & \\
\hline & G & $1812(77.3)$ & $215(64.8)$ & $1.8 \mathrm{E}-06^{\mathrm{b}}$ & $149(70.3)$ & $0.03^{\mathrm{b}}$ \\
\hline & $\mathrm{C}$ & $532(22.7)$ & $117(35.2)$ & & $63(29.7)$ & \\
\hline & G & $434(28.6)$ & $122(36.7)$ & & $66(31.1)$ & \\
\hline \multirow[t]{5}{*}{ Mdm2 (rs 2279744) } & $\mathrm{TT}$ & $534(40.8)$ & $48(28.9)$ & $0.05^{\mathrm{b}}$ & $37(34.9)$ & 0.70 \\
\hline & TG & $571(43.7)$ & $88(53.0)$ & & $49(46.2)$ & \\
\hline & GG & $203(15.5)$ & $30(18.1)$ & & 20 (18.9) & \\
\hline & $\mathrm{T}$ & $1639(62.7)$ & $184(55.7)$ & $0.03^{\mathrm{b}}$ & $123(58.0)$ & 0.35 \\
\hline & G & $977(37.3)$ & $148(44.3)$ & & $89(42.0)$ & \\
\hline \multirow[t]{5}{*}{ Mdm4 (rs1563828) } & $\mathrm{CC}$ & $606(48.0)$ & $62(37.3)$ & 0.07 & $42(39.6)$ & $0.01^{\mathrm{b}}$ \\
\hline & TC & $515(40.8)$ & $81(48.8)$ & & $41(38.7)$ & \\
\hline & $\mathrm{TT}$ & $142(11.2)$ & $23(13.8)$ & & $23(21.7)$ & \\
\hline & $\mathrm{C}$ & $1727(68.4)$ & $205(61.7)$ & $0.05^{\mathrm{b}}$ & $125(59.0)$ & $0.02^{\mathrm{b}}$ \\
\hline & $\mathrm{T}$ & $799(31.6)$ & $127(38.3)$ & & $87(41.0)$ & \\
\hline \multirow[t]{5}{*}{ Hausp (rs 1529916) } & GG & $45(45.0)$ & $61(36.7)$ & $0.003^{\mathrm{b}}$ & $51(40.2)$ & $0.05^{\mathrm{b}}$ \\
\hline & GA & $47(47.0)$ & $64(38.6)$ & & $36(38.2)$ & \\
\hline & AA & $8(8.0)$ & $41(24.7)$ & & 19 (17.9) & \\
\hline & G & $137(68.5)$ & $186(56.0)$ & $0.004^{\mathrm{b}}$ & $138(65.1)$ & 0.46 \\
\hline & A & $63(31.5)$ & $146(44.0)$ & & 74 (34.9) & \\
\hline \multirow[t]{5}{*}{ LIF (rs 929271) } & TT & $406(53.6)$ & $65(39.1)$ & $0.01^{\mathrm{b}}$ & $50(47.2)$ & 0.48 \\
\hline & GT & $270(35.6)$ & $80(48.2)$ & & $46(43.4)$ & \\
\hline & GG & $82(10.8)$ & $21(12.7)$ & & $10(9.4)$ & \\
\hline & $\mathrm{T}$ & $1082(71.4)$ & $210(63.3)$ & $0.008^{\mathrm{b}}$ & $146(68.9)$ & 0.43 \\
\hline & G & $434(28.6)$ & $122(36.7)$ & & $66(31.1)$ & \\
\hline
\end{tabular}

IVF patients were recruited at Weill Cornell Medical College. Lymphoblastoid cell lines established from 100 healthy Caucasian individuals and women recruited as controls for the Women's Insights and Shared Experiences (WISE) study were used as controls. ${ }^{\mathrm{a}} \mathrm{Chi}$-Squared Test; ${ }^{\mathrm{b}}$ Significant difference was observed between IVF patients and controls.

strongly suggest a role of p53 in regulation of human reproduction.

Interestingly, the majority of these at-risk alleles in the p53 pathway for human fertility mainly act on young patients and their effects disappear or are reduced in older patients, such as, women over the age of 35-40 years (Table 1) (Kang et al. 2009). Maternal age has a significant negative impact on fertility, and a major underlying mechanism for infertility in older patients is aneuploidy of oocytes and poor quality of embryos. It is possible that in older patients with infertility, factors such as aneuploidy, instead of impaired implantation (low levels of LIF) as observed in young patients, may predominate. Considering the important functions of p63 and p73 in maintaining female germ-cell integrity to prevent aneuploidy, the enrichment of selected alleles or mutations in these genes may be observed in older female patients with infertility. In humans, mutation of p63 is associated with several autosomal dominantly inherited syndromes, including EEC syndrome (ectrodactyly, ectodermal dysplasia, and cleft lip/palate), AEC syndrome (ankyloblepharon, ectodermal dysplasia, and clefting), ADULT syndrome (acro-dermato-ungual-lacrimal-tooth syndrome), RHS syndrome (the Rapp-Hodgkin syndrome), limb-mammary syndrome, and nonsyndromic split hand/foot 
malformation (Celli et al. 1999; van Bokhoven et al. 2001; Brunner et al. 2002). Most of these syndromes are characterized by limb abnormalities. Interestingly, four affected adult females from one family with a p63 mutation presenting with RHS syndrome all showed premature menopause and infertility (Holder-Espinasse et al. 2007). These data are consistent with the idea that p63 may also play an important role in maintaining the female germ-line integrity and ovary function in humans.

In summary, it is clear that a p53/p63/p73like ancestor gene developed at early times during evolution. The primordial functions of this gene in lower organisms are to ensure faithful development, germ-line genomic integrity and fecundity or the production of normal offspring that will survive and reproduce. These same functions appear to be conserved in vertebrates, including mice and humans, which suggest that tumor suppression is not the original function of the p53 ancestor gene, which appears later in evolution. The role of p53, p63, and p73 in female fertility and genomic integrity suggests that these genes will become important contributors to understand other disease processes in addition to cancers. For example, genomic instability, aneuploidy, and copy-number polymorphisms that originate in the female germ line and contribute to a number of developmental defects could be genetically monitored by exploring different alleles in the p63, p73, and p53 genes and this might indicate an age-related risk for these defects. A better understanding of these processes can also contribute to the development of therapies that reduce the incidence of infertility. Evolutionary selection pressures often arise from differences in fecundity, food consumption efficiencies, and resistance to infectious diseases. The reproductive functions of the p53 family of genes provide a plausible explanation of the evolutionary positive selection of some alleles in the p53 pathway, which impacts on the activities and functions of this group of genes. The broad functions of the p53 family of gene products in reproduction, fertility, cancer, and life span show a cooperative pleiotropy in which the same alleles are selected for optimal reproduction and cancer prevention, but these same observations provide a good example of antagonistic pleiotropy when the phenotypes of fertility and life span are compared. Understanding the roles of these gene products in fertility and development will provide new insights into our understanding of many diverse disease processes.

\section{REFERENCES}

Atwal GS, Bond GL, Metsuyanim S, Papa M, Friedman E, Distelman-Menachem T, Ben Asher E, Lancet D, Ross DA, Sninsky J, et al. 2007. Haplotype structure and selection of the MDM2 oncogene in humans. Proc Natl Acad Sci 104: 4524-4529.

Atwal GS, Kirchhoff T, Bond EE, Menin C, Bertorelle R, Bartel F, Bohnke A, Gradhand E, Hauptmann S, Offit $\mathrm{K}$, et al. 2009. Evolutionary selection and altered tumor formation of genetic variants in the human Mdm4 oncogene. Proc Natl Acad Sci 106: 10236-10241.

Baker DJ, Jeganathan KB, Cameron JD, Thompson M, Juneja S, Kopecka A, Kumar R, Jenkins RB, de Groen PC, et al. 2004. BubR1 insufficiency causes early onset of aging-associated phenotypes and infertility in mice. Nat Genet 36: 744-749.

Banga SS, Yamamoto AH, Mason JM, Boyd JB. 1995. Molecular cloning of mei-41, a gene that influences both somatic and germline chromosome metabolism of Drosophila melanogaster. Mol Gen Genet 246: 148-155.

Belyi V, Ak P, Markert E, Wang H, Hu W, Puzio-Kuter A, Levine AJ. 2010. The origins and evolution of the p53 family of genes. Cold Spring Harb Perspect Biol 2: a001198.

Bennett WP, Hussain SP, Vahakangas KH, Khan MA, Shields PG, Harris CC. 1999. Molecular epidemiology of human cancer risk: Gene-environment interactions and p53 mutation spectrum in human lung cancer. J Pathol 187: 8-18.

Bond GL, Hu W, Bond EE, Robins H, Lutzker SG, Arva NC, Bargonetti J, Bartel F, Taubert H, Wuerl P, et al. 2004. A single nucleotide polymorphism in the MDM2 promoter attenuates the p53 tumor suppressor pathway and accelerates tumor formation in humans. Cell 119: 591-602.

Bourdon JC, Fernandes K, Murray-Zmijewski F, Liu G, Diot A, Xirodimas DP, Saville MK, Lane DP. 2005. p53 isoforms can regulate p53 transcriptional activity. Genes Dev 19: 2122-2137.

Brodsky MH, Nordstrom W, Tsang G, Kwan E, Rubin GM Abrams JM. 2000a. Drosophila p53 binds a damage response element at the reaper locus. Cell 101: 103-113.

Brodsky MH, Sekelsky JJ, Tsang G, Hawley RS, Rubin GM. 2000b. mus304 encodes a novel DNA damage checkpoint protein required during Drosophila development. Genes Dev 14: 666-678.

Brooks CL, Li M, Hu M, Shi Y, Gu W. 2007. The p53Mdm2-HAUSP complex is involved in p53 stabilization by HAUSP. Oncogene 26: 7262-7266. 
W. Hu

Brunner HG, Hamel BC, Van Bokhoven H. 2002. The p63 gene in EEC and other syndromes. J Med Genet 39: 377-381.

Canman CE, Lim DS, Cimprich KA, Taya Y, Tamai K, Sakaguchi K, Appella E, Kastan MB, Siliciano JD. 1998. Activation of the ATM kinase by ionizing radiation and phosphorylation of p53. Science 281: 1677-1679.

Celli J, Duijf P, Hamel BC, Bamshad M, Kramer B, Smits AP, Newbury-Ecob R, Hennekam RC, Van Buggenhout G, van Haeringen A, et al. 1999. Heterozygous germline mutations in the p53 homolog p63 are the cause of EEC syndrome. Cell 99: 143-153.

Chen JR, Cheng JG, Shatzer T, Sewell L, Hernandez L, Stewart CL. 2000. Leukemia inhibitory factor can substitute for nidatory estrogen and is essential to inducing a receptive uterus for implantation but is not essential for subsequent embryogenesis. Endocrinology 141: $4365-$ 4372.

Cheng R, Ford BL, O'Neal PE, Mathews CZ, Bradford CS, Thongtan T, Barnes DW, Hendricks JD, Bailey GS 1997. Zebrafish (Danio rerio) p53 tumor suppressor gene: cDNA sequence and expression during embryogenesis. Mol Mar Biol Biotechnol 6: 88-97.

Derry WB, Putzke AP, Rothman JH. 2001. Caenorhabditis elegans p53: Role in apoptosis, meiosis, and stress resistance. Science 294: 591-595.

Dumont P, Leu JI, Della Pietra AC 3rd, George DL, Murphy M. 2003. The codon 72 polymorphic variants of $p 53$ have markedly different apoptotic potential. Nat Genet 33: 357-365.

Fernandes AD, Atchley WR. 2008. Biochemical and functional evidence of p53 homology is inconsistent with molecular phylogenetics for distant sequences. $J \mathrm{Mol}$ Evol 67: 51-67.

Gardner RD, Burke DJ. 2000. The spindle checkpoint: Two transitions, two pathways. Trends Cell Biol 10: 154-158.

Harris SL, Levine AJ. 2005. The p53 pathway: Positive and negative feedback loops. Oncogene 24: 2899-2908.

Hasegawa M, Zhang Y, Niibe H, Terry NH, Meistrich ML. 1998. Resistance of differentiating spermatogonia to radiation-induced apoptosis and loss in p53-deficient mice. Radiat Res 149: 263-270.

Hirao A, Kong YY, Matsuoka S, Wakeham A, Ruland J, Yoshida H, Liu D, Elledge SJ, Mak TW. 2000. DNA damage-induced activation of $\mathrm{p} 53$ by the checkpoint kinase Chk2. Science 287: 1824-1827.

Hoever M, Clement JH, Wedlich D, Montenarh M, Knochel W. 1994. Overexpression of wild-type p53 interferes with normal development in Xenopus laevisembryos. Oncogene 9: 109-120.

Holder-Espinasse M, Martin-Coignard D, Escande F, Manouvrier-Hanu S. 2007. A new mutation in TP63 is associated with age-related pathology. Eur J Hum Genet 15: 1115-1120.

Hu W, Feng Z, Atwal GS, Levine AJ. 2008. p53: A new player in reproduction. Cell Cycle 7: 848-852.

Hu W, Feng Z, Ma L, Wagner J, Rice JJ, Stolovitzky G, Levine AJ. 2007a. A single nucleotide polymorphism in the MDM2 gene disrupts the oscillation of p53 and MDM2 levels in cells. Cancer Res 67: 2757-2765.
Hu W, Feng Z, Teresky AK, Levine AJ. 2007b. p53 regulates maternal reproduction through LIF. Nature 450: $721-724$.

Jin S, Martinek S, Joo WS, Wortman JR, Mirkovic N, Sali A, Yandell MD, Pavletich NP, Young MW, Levine AJ. 2000. Identification and characterization of a p53 homologue in Drosophila melanogaster. Proc Natl Acad Sci 97: 7301-7306.

Kang HJ, Feng Z, Sun Y, Atwal G, Murphy ME, Rebbeck TR, Rosenwaks Z, Levine AJ, Hu W. 2009. Single-nucleotide polymorphisms in the $\mathrm{p} 53$ pathway regulate fertility in humans. Proc Natl Acad Sci 106: 9791-9766.

Kay C, Jeyendran RS, Coulam CB. 2006. p53 tumour suppressor gene polymorphism is associated with recurrent implantation failure. Reprod Biomed Online 13: 492-496.

Kelley ML, Winge P, Heaney JD, Stephens RE, Farell JH, Van Beneden RJ, Reinisch CL, Lesser MP, Walker CW. 2001 Expression of homologues for p53 and p73 in the softshell clam (Mya arenaria), a naturally-occurring model for human cancer. Oncogene 20: 748-758.

Kobayashi S. 2004a. Developmental expression of p63 in the mouse testis. J Vet Med Sci 66: 681-687.

Kobayashi S. 2004b. Expression of p63 in the mouse primordial germ cells. J Vet Med Sci 66: 1365-1370.

Kurita T, Mills AA, Cunha GR. 2004. Roles of p63 in the diethylstilbestrol-induced cervicovaginal adenosis. Development 131: 1639-1649.

Kurita T, Cunha GR, Robboy SJ, Mills AA, Medina RT. 2005. Differential expression of $\mathrm{p} 63$ isoforms in female reproductive organs. Mech Dev 122: 1043-1055.

Lee JH, Lee E, Park J, Kim E, Kim J, Chung J. 2003. In vivo p53 function is indispensable for DNA damage-induced apoptotic signaling in Drosophila. FEBS Lett 550: 5-10.

Levine AJ, Hu W, Feng Z. 2006. The P53 pathway: What questions remain to be explored? Cell Death Differ 13: 1027-1036.

Livera G, Petre-Lazar B, Guerquin MJ, Trautmann E, Coffigny H, Habert R. 2008. p63 null mutation protects mouse oocytes from radio-induced apoptosis. Reproduction 135: 3-12.

Mason JM, Green MM, Shaw KE, Boyd JB. 1981. Genetic analysis of X-linked mutagen-sensitive mutants of Drosophila melanogaster. Mutat Res 81: 329-343.

Melino G, Lu X, Gasco M, Crook T, Knight RA. 2003. Functional regulation of p73 and p63: Development and cancer. Trends Biochem Sci 28: 663-670.

Mikolajczyk M, Wirstlein P, Skrzypczak J. 2007. The impact of leukemia inhibitory factor in uterine flushing on the reproductive potential of infertile women-a prospective study. Am J Reprod Immunol 58: 65-74.

Mills AA, Zheng B, Wang XJ, Vogel H, Roop DR, Bradley A. 1999. p63 is a p53 homologue required for limb and epidermal morphogenesis. Nature 398: 708-713.

Moll UM, Slade N. 2004. p63 and p73: Roles in development and tumor formation. Mol Cancer Res 2: 371-386.

Murphy ME. 2006. Polymorphic variants in the p53 pathway. Cell Death Differ 13: 916-920.

Nakamuta N, Kobayashi S. 2003. Expression of p63 in the testis of mouse embryos. J Vet Med Sci 65: 853-856. 
Nedelcu AM, Tan C. 2007. Early diversification and complex evolutionary history of the p53 tumor suppressor gene family. Dev Genes Evol 217: 801-806.

Nicol CJ, Harrison ML, Laposa RR, Gimelshtein IL, Wells PG. 1995. A teratologic suppressor role for p53 in benzo[a]pyrene-treated transgenic p53-deficient mice. Nat Genet 10: 181-187.

Norimura T, Nomoto S, Katsuki M, Gondo Y, Kondo S 1996. p53-dependent apoptosis suppresses radiationinduced teratogenesis. Nat Med 2: 577-580.

Ollmann M, Young LM, Di Como CJ, Karim F, Belvin M, Robertson S, Whittaker K, Demsky M, Fisher WW Buchman A, et al. 2000. Drosophila p53 is a structural and functional homolog of the tumor suppressor p53. Cell 101: 91-101.

Pankow S, Bamberger C. 2007. The p53 tumor suppressorlike protein nvp63 mediates selective germ cell death in the sea anemone Nematostella vectensis. PLoS ONE 2: pe782.

Pim D, Banks L. 2004. p53 polymorphic variants at codon 72 exert different effects on cell cycle progression. Int $J$ Cancer 108: 196-199.

Rotter V, Schwartz D, Almon E, Goldfinger N, Kapon A, Meshorer A, Donehower LA, Levine AJ. 1993. Mice with reduced levels of p53 protein exhibit the testicular giant-cell degenerative syndrome. Proc Natl Acad Sci 90: 9075-9079.

Salvioli S, Bonafe M, Barbi C, Storci G, Trapassi C, Tocco F Gravina S, Rossi M, Tiberi L, Mondello C, et al. 2005. p53 codon 72 alleles influence the response to anticancer drugs in cells from aged people by regulating the cell cycle inhibitor p21WAF1. Cell Cycle 4: 1264-1271.

Schmid P, Lorenz A, Hameister H, Montenarh M. 1991. Expression of p53 during mouse embryogenesis. Development 113: 857-865.

Shieh SY, Ahn J, Tamai K, Taya Y, Prives C. 2000. The human homologs of checkpoint kinases Chk1 and Cds1 (Chk2) phosphorylate p53 at multiple DNA damage-inducible sites. Genes Dev 14: 289-300.

Sogame N, Kim M, Abrams JM. 2003. Drosophila p53 preserves genomic stability by regulating cell death. Proc Natl Acad Sci 100: 4696-4701.

Soussi T, Caron de Fromentel C, Mechali M, May P, Kress M. 1987. Cloning and characterization of a cDNA from Xenopus laeviscoding for a protein homologous to human and murine p53. Oncogene 1: 71-78.

Spandorfer SD, Davis OK, Barmat LI, Chung PH, Rosenwaks Z. 2004. Relationship between maternal age and aneuploidy in in vitro fertilization pregnancy loss. Fertil Steril 81: 1265-1269.

Stewart CL, Kaspar P, Brunet LJ, Bhatt H, Gadi I, Kontgen F, Abbondanzo SJ. 1992. Blastocyst implantation depends on maternal expression of leukaemia inhibitory factor. Nature 359: 76-79.

Suh EK, Yang A, Kettenbach A, Bamberger C, Michaelis AH, Zhu Z, Elvin JA, Bronson RT, Crum CP, McKeon F. 2006. p63 protects the female germ line during meiotic arrest. Nature 444: 624-628.

Sullivan A, Syed N, Gasco M, Bergamaschi D, Trigiante G, Attard M, Hiller L, Farrell PJ, Smith P, Lu X, Crook T. 2004. Polymorphism in wild-type p53 modulates response to chemotherapy in vitro and in vivo. Oncogene 23: 3328-3337.

Taylor SS, Scott MI, Holland AJ. 2004. The spindle checkpoint: A quality control mechanism which ensures accurate chromosome segregation. Chromosome Res 12: 599-616.

Tomasini R, Tsuchihara K, Tsuda C, Lau SK, Wilhelm M, Ruffini A, Tsao MS, Iovanna JL, Jurisicova A, Melino G, et al. 2009. TAp73 regulates the spindle assembly checkpoint by modulating BubR1 activity. Proc Natl Acad Sci 106: $797-802$.

Tomasini R, Tsuchihara K, Wilhelm M, Fujitani M, Rufini A, Cheung CC, Khan F, Itie-Youten A, Wakeham A, Tsao MS, et al. 2008. TAp73 knockout shows genomic instability with infertility and tumor suppressor functions. Genes Dev 22: 2677-2691.

Tsai HD, Chang CC, Hsieh YY, Lo HY. 2000. Leukemia inhibitory factor expression in different endometrial locations between fertile and infertile women throughout different menstrual phases. J Assist Reprod Genet 17: $415-418$.

van Bokhoven H, Hamel BC, Bamshad M, Sangiorgi E, Gurrieri F, Duijf PH, Vanmolkot KR, van Beusekom E, van Beersum SE, Celli J. 2001. p63 Gene mutations in eec syndrome, limb-mammary syndrome, and isolated split hand-split foot malformation suggest a genotypephenotype correlation. Am J Hum Genet 69: 481-492.

Vogelstein B, Lane D, Levine AJ. 2000. Surfing the p53 network. Nature 408: 307-310.

Vogiagis D, Salamonsen LA. 1999. Review: The role of leukaemia inhibitory factor in the establishment of pregnancy. J Endocrinol 160: 181-190.

Xu J, Xin S, Du W. 2001. Drosophila Chk2 is required for zDNA damage-mediated cell cycle arrest and apoptosis. FEBS Lett 508: 394-398.

Yang A, Kaghad M, Wang Y, Gillett E, Fleming MD, Dotsch V, Andrews NC, Caput D, McKeon F. 1998. p63, a p53 homolog at 3q27-29, encodes multiple products with transactivating, death-inducing, and dominant-negative activities. Mol Cell 2: 305-316.

Yang A, Schweitzer R, Sun D, Kaghad M, Walker N, Bronson RT, Tabin C, Sharpe A, Caput D, Crum C, et al. 1999. p63 is essential for regenerative proliferation in limb, craniofacial and epithelial development. Nature 398: 714-718.

Yang A, Walker N, Bronson R, Kaghad M, Oosterwegel M, Bonnin J, Vagner C, Bonnet H, Dikkes P, Sharpe A, et al. 2000. p73-deficient mice have neurological, pheromonal and inflammatory defects but lack spontaneous tumours. Nature 404: 99-103. 


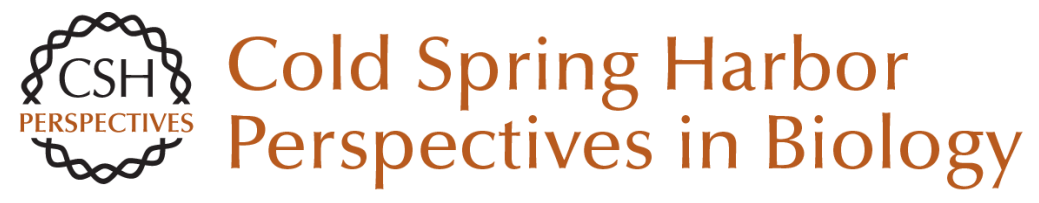

\section{The Role of p53 Gene Family in Reproduction}

Wenwei Hu

Cold Spring Harb Perspect Biol 2009; doi: 10.1101/cshperspect.a001073 originally published online October 28, 2009

\section{Subject Collection The p53 Family}

The Origins and Evolution of the p53 Family of Genes

Vladimir A. Belyi, Prashanth Ak, Elke Markert, et al.

Mouse Models of p53 Functions

Guillermina Lozano

TP53 Mutations in Human Cancers: Origins,

Consequences, and Clinical Use

Magali Olivier, Monica Hollstein and Pierre Hainaut

p53 Research: The Past Thirty Years and the Next

Thirty Years

David Lane and Arnold Levine

Transcriptional Regulation by P53

Rachel Beckerman and Carol Prives

p53-based Cancer Therapy

David P. Lane, Chit Fang Cheok and Sonia Lain

Phylogeny and Function of the Invertebrate p53

Superfamily

Rachael Rutkowski, Kay Hofmann and Anton Gartner

Tied Up in Loops: Positive and Negative

Autoregulation of p53

Xin Lu
The Tumor Suppressor p53: From Structures to

Drug Discovery

Andreas C. Joerger and Alan R. Fersht

p53 Regulation of Metabolic Pathways

Eyal Gottlieb and Karen H. Vousden

The Regulation of the p53-mediated Stress

Response by MDM2 and MDM4 Mary Ellen Perry

Zebrafish Models of p53 Functions Narie Y. Storer and Leonard I. Zon

p63 and p73, the Ancestors of p53

V. Dötsch, F. Bernassola, D. Coutandin, et al.

Pathologies Associated with the p53 Response Andrei V. Gudkov and Elena A. Komarova

Single-nucleotide Polymorphisms in the p53

Signaling Pathway

Lukasz F. Grochola, Jorge Zeron-Medina, Sophie Mériaux, et al.

Clinical Outcomes and Correlates of TP53

Mutations and Cancer

Ana I. Robles and Curtis C. Harris

For additional articles in this collection, see http://cshperspectives.cshlp.org/cgi/collection/

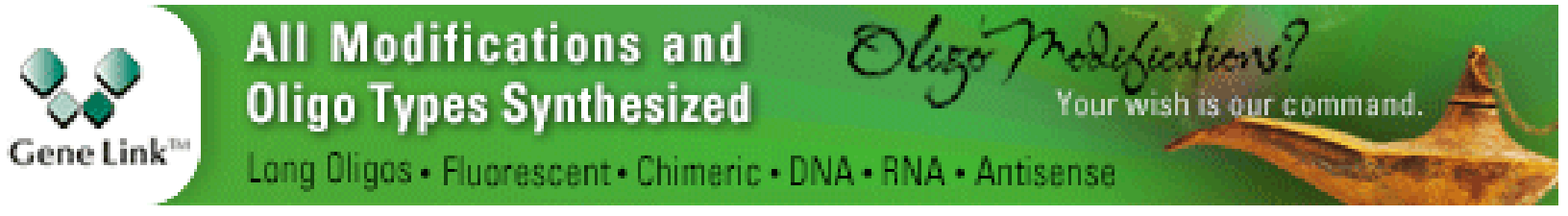

Copyright @ 2009 Cold Spring Harbor Laboratory Press; all rights reserved 